\title{
Effect of Commercial Plant Growth Regulator on the Growth of Dragon Fruit (Hylocereus sp.) Cuttings under Greenhouse Condition
}

\author{
Arkheanne Angelic G. Dano ${ }^{1}$,Renaldy L. Tupas ${ }^{2}$, and Lynn Esther E. Rallos ${ }^{1 *}$ \\ ${ }^{1}$ Science Department, College of Natural Sciences and Mathematics, Mindanao State \\ University-General Santos, Fatima, General Santos City 9500 Philippines \\ ${ }^{2}$ Department of Agronomy, College of Agriculture, Mindanao State \\ University-General Santos, Fatima, General Santos City 9500 Philippines \\ *Corresponding author: +639152735589; lynnesther.rallos@msugensan.edu.ph
}

Received: February 27, 2020; Accepted: May 8, 2020

\begin{abstract}
Information is limited on the effects of commercial plant growth regulators (PGRs) on dragon fruit. Most studies on rooting effects on dragon fruit cuttings employed very high doses of plant growth regulators (PGRs), which are not deemed practical for greenhouse and field applications. This study was initiated to evaluate the responses of four genotypes of dragon fruit ('Royal Red', 'Moroccan Red', 'Mexican White', and 'Hawaiian White') during greenhouse acclimatization to diluted concentrations of commercial PGRs that are readily available in the market. A single factorial experiment on genotype effects on root and shoot responses, without PGR, was conducted. A second experiment with a 4x3 2 completely randomized design, with four genotypes, three diluted commercial PGR formulations and two exposure times as factors was also done. Root length, number of roots, number of days to first shoot emergence and number of new shoots were measured after 50 days of acclimatization in the greenhouse. In the single factorial experiment, only 'genotype' had an effect on number of new shoots $(P<0.05)$. In the multifactorial experiment, all factors tested did not have significant interaction effects. However, the main effect of 'genotype' on number of new shoots and number of days to first shoot emergence was also significant $(P<0.05)$. The lack of significant effect of other factors and their interactions on most growth responses suggest that it is difficult to resolve differences among the four genotypes using highly diluted commercial PGR formulations after a 50-day observation period. However, our data still suggest that the 'Red' genotypes are more superior than the 'White' genotypes in terms of shoot growth.
\end{abstract}

Keywords: dragon fruit, greenhouse acclimatization, plant growth regulators, rooting performance, shoot response

The production of dragon fruit (Hylocereus $s p$.) has become a profitable industry among countries across Asia. It has gone from backyard planting to a business scale in many tropical regions where agro-environmental conditions are favorable for cultivation[1]. These include Vietnam and other southeast Asian countries like Malaysia, Taiwan and the Philippines. In 2015, Vietnam planted dragon fruit in a total land area of 41,164 hectares, which produced 600,000 tons of fruit, making the country the leading exporter of dragon fruit in the world [2]. Even if the Philippines has not yet achieved this volume, the country's production showed an increasing growth rate in a period of six years, from 2012 to 2017. The Philippines produced 1,462 $\mathrm{mt}$ of dragon fruit in 2017 from only $256 \mathrm{mt}$ in 2012, with Ilocos as the highest producer [3]. The observed trend can be attributed to the fact that dragon fruit is a high yielding crop [4]. 
The success of dragon fruit production among agricultural producers, exporters, and consumers all over Asia is due to a number of reasons. Aside from high net returns, dragon fruit has a promising functional property with its high anti-oxidant content such as betalain [5]. The fruit is also loaded with nutrients and minerals like vitamin $\mathrm{C}$, vitamins $\mathrm{B} 1, \mathrm{~B} 2$ and $\mathrm{B} 3$, protein and phytoalbumins [6]. It is also believed to help in reducing the risk of acquiring oxidative-stress related disorders, such as diabetes mellitus, cardiovascular diseases, and hypertension by eating the fruit itself.

Dragon fruit can be propagated in two ways, either through seed or by stem cuttings. Due to cross pollination and slow growth rate of fruits by means of seed cultivation, dragon fruit planting is primarily based on stem cuttings for clonal propagation and faster fruiting [5]. Dragon fruit propagated through stem cuttings starts to bear fruits twelve to eighteen months after planting, as opposed to three years for plants grown from seeds. Cutting off the stem from the mother plant is convenient because the stem can be directly and easily removed after the fruiting season. However, stem cuttings are also prone to decreased productivity due to rooting issues [7]. In some dragon fruit cultivars, like $H$. undatus, cuttings do not root easily without the use of auxin treatment, and have extended root initiation time, lesser number of roots and shorter root length compared to treated cuttings [9]. However, effects observed on root performance of $H$. undatus were a result of the application of high concentrations of auxins. Previous studies found that the application of IBAwas effective at a concentration ranging from $6000 \mathrm{ppm}$ to $7000 \mathrm{ppm}$ [9-10]. These concentrations are surprising given the knowledge that auxins are effective even at very low concentrations and auxins applied at high dose may actually be damaging [11]. These findings drive home the importance of testing plant growth regulators (PGRs) such as auxins at concentrations lower than those previously tested under local conditions.

Presently, experiment-driven data on the effects of auxin treatment using diluted PGR products on specific varieties of dragon fruit grown in the greenhouse are not yet available. The major objective of this study was to evaluate the growth responses of dragon fruit (Hylocereus sp.) genotypes treated with diluted commercial PGRs while acclimatizing in the greenhouse located at Mindanao State University-General Santos City.
Specifically, we aimed to (1) evaluate the root and shoot growth responses of cuttings of four dragon fruit genotypes namely, 'Hawaiian White', 'Mexican White', 'Moroccan Red' and 'Royal Red' while acclimatizing in the greenhouse for 50 days; and (2) determine the effects of exposure times (10 s and $15 \mathrm{~min}$ ) to diluted concentrations of solo NAA or mixed NAA and IBA commercial formulations on their growth during greenhouse acclimatization.

\section{Materials and Methods}

\section{Study Site}

The experiments were performed in the greenhouse building facility of the College of Natural Sciences and Mathematics, Mindanao State University-General Santos City $\left(6.0662^{\circ} \mathrm{N}\right.$, $\left.125.1267^{\circ} \mathrm{E}\right)$ from September to December 2018. The greenhouse afforded approximately $40 \%$ shading and an average noontime and daytime (9:00 am) temperature of $33.2{ }^{\circ} \mathrm{C} \pm 0.37$ and $25.4^{\circ} \mathrm{C} \pm 0.51$, respectively.

\section{Collection and Processing of Dragon Fruit Cuttings}

The dragon fruit cuttings came from Maryland Dragon Fruit Gardens $\left(7.4859^{\circ} \mathrm{N}\right.$, $125.8349^{\circ} \mathrm{E}$ ), Barangay San Agustin, Tagum City, Davao del Norte. Four genotypes of dragon fruit identified by the grower as 'Hawaiian White', 'Mexican White', 'Moroccan Red' and 'Royal Red' were purchased from the farm. Pruning shears were used to remove the stem cuttings from the mother plant. Dirt was washed off with tap water and dishwashing soap. The cuttings were sprayed with Topsin (Trans World Trading Co., Inc., Makati City, Philippines) using the manufacturer's labeled rate in a manner that achieved full coverage. The cuttings were air-dried, labelled and packed in a box for transport to the laboratory. The base of the cuttings was trimmed and stored in a box for three days for wound healing and recovery.

\section{Soil Media Mix Preparation}

The potting soil mixture was composed of $31 \%$ garden soil, $28 \%$ vermicast soil, $4 \%$ dry cow dung (pulverized), 34\% sand and 3\% saw dust. Dry cow dung was collected from the Animal Science pasture land in MSU-GSC, while sand was collected from a construction pile in the College of Natural Sciences and Mathematics compound. Garden soil and vermicast soil were bought from garden stores. The components were mixed well 
and placed in 7 in $x 7$ in x 11 in polyethylene bags, with approximately $2.5 \mathrm{~kg}$ per bag.

\section{Experimental Set-ups}

A single factor experiment on genotype effects on root and shoot response (no PGR treatment) was conducted for collection of baseline data. Nine stem cuttings per genotype were used for the experiment.

A second experiment based on a $4 \times 3 \times 2$ completely randomized design was conducted. The factors were as follows: four different genotypes as Factor A, three commercial PGR formulations as Factor B and two different exposure times (10s and $15 \mathrm{~min}$ ) as Factor $\mathrm{C}$. Three PGR products were used, namely, ANAA (Philippine Orchard Corporation, Makati City, Philippines), Hormex (Ramgo International Corporation, Pasig City, Philippines) and Siam (Artformic Corporation, Quezon City, Philippines). PGR solutions were prepared according to the volumes calculated for each hormone (Table 1) to achieve uniform concentration of Vitamin B1, a common component across three products, and relatively high, moderate or low concentrations of NAA and IBA. Three PGR solutions were prepared: (1) high NAA, no IBA (ANAA), (2) moderate NAA, high IBA (Hormex) and (3) low NAA and IBA (Siam). The actual concentration of the active ingredient in the commercial products was not indicated in the label; thus, the hormone concentration was calculated based on the percentage indicated in the label. The base of three stem cuttings per genotype was dipped in the prepared hormone solution for $10 \mathrm{~s}$ (immediate, label recommendation) or $15 \mathrm{~min}$ (extended). The treated cuttings were air-dried before planting.

Cuttings from both experiments were planted in the soil mix, with about 2 in of the base buried in the soil. The cuttings were randomly arranged in the greenhouse which was approximately $40 \%$ shaded with an average noontime and daytime temperature of $30^{\circ} \mathrm{C} \pm 0.37$ (around 9:00 $\mathrm{AM}$ ) and $28^{\circ} \mathrm{C} \pm 0.51$, respectively.

\section{Plant Management}

Cuttings were observed regularly for any ant invasion and disease such as stem rot. For ant control, 1:1 v/v white vinegar and liquid dishwashing soap (Joy) solution was sprayed on the cuttings and the soil, once daily for four days or until ants were no longer observed. Stem cuttings, with or without new shoots, observed with ant infestation were recorded. For stem rot control, putrid portions were removed by scraping rotten tissue prior to the application of fungicide or bactericide. Kocide ${ }^{\circledR}$ (Du Pont Far East, Pasig City, Philippines) was applied on all the cuttings according to the manufacturer's instructions. Gloves and masks were used during preparation and spraying. Individual stem cuttings with stem rot were also recorded.

\section{Data Collection}

Growth responses measured were root length, number of roots, number of days to first shoot emergence and number of new shoots.

After 50 days, individual stem cuttings were gently pulled out of the soil. To avoid damaging the root system, the entire plant base with roots and soil was soaked in water to dislodge bulk soil. The roots were washed gently in tap water until main roots were visible for counting. Main roots are those directly connected to the central stem at the base of the cutting (Figure 1). These roots were counted and recorded. Root length was measured as the length from the highest point of root-stem attachment (base of cutting) to the tip of the mass of roots gathered into a loose bundle. The root length was measured using a

Table 1. Concentration of hormones for the preparation of commercial PGR solutions with NAA, IBA and Vitamin B1 for the multifactorial experiment on dragon fruit cuttings.

\begin{tabular}{|c|c|c|c|}
\hline & ANAA & Hormex & SIAM \\
\hline Label recommendation & $15 \mathrm{ml}$ in $4 \mathrm{~L} \mathrm{H}_{2} \mathrm{O}$ & $10 \mathrm{ml}$ in $4 \mathrm{~L} \mathrm{H}_{2} \mathrm{O}$ & $15 \mathrm{ml}$ in $4 \mathrm{~L} \mathrm{H}_{2} \mathrm{O}$ \\
\hline Dose used in present study & $45 \mathrm{ml}$ in $4 \mathrm{~L} \mathrm{H}_{2} \mathrm{O}$ & $10 \mathrm{ml}$ in $4 \mathrm{~L} \mathrm{H}_{2} \mathrm{O}$ & $15 \mathrm{ml}$ in $4 \mathrm{~L} \mathrm{H}_{2} \mathrm{O}$ \\
\hline Final NAA concentration & $0.001125 \%$ & $0.0006 \%$ & $0.00015 \%$ \\
\hline Final IBA concentration & $0 \%$ & $0.000325 \%$ & $0.0000075 \%$ \\
\hline Final Vitamin B1 concentration & $0.0005625 \%$ & $0.000625 \%$ & $0.0006 \%$ \\
\hline Treatment description & $\begin{array}{l}\text { high NAA, } \\
\text { no IBA }\end{array}$ & $\begin{array}{l}\text { moderate NAA, } \\
\text { high IBA }\end{array}$ & $\begin{array}{l}\text { low NAA, } \\
\text { low IBA }\end{array}$ \\
\hline
\end{tabular}




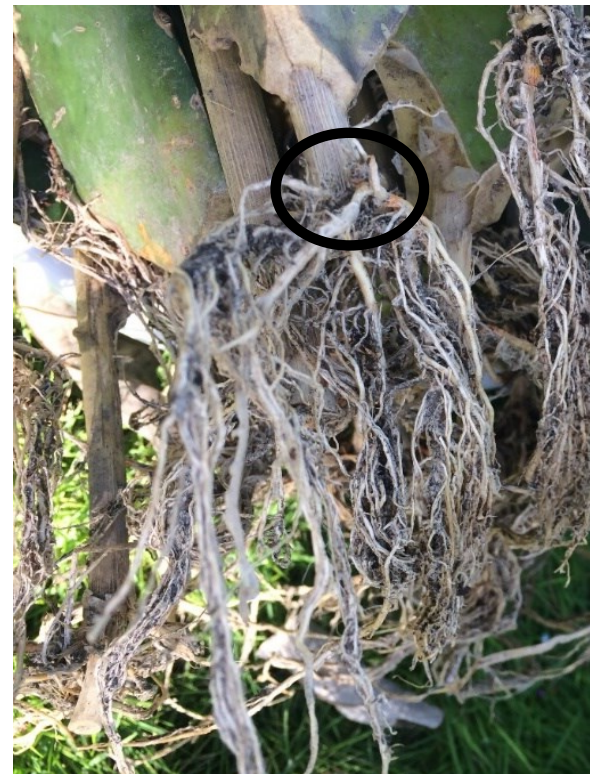

Figure 1. Main roots of dragon fruit cutting attached to the stem (black circle) and counted after 50 days of acclimatization in the greenhouse.

meter stick. The date and the number of days after new shoot has emerged from the stem cuttings were recorded from 1 to 51 days, with 51 days for no shoot emerged. The number of new shoots per cutting was also counted during the last day of the experiment. New shoots that were dead due to rot formation were not included in the count.

\section{Statistical analysis}

Prior to analyses, root and shoot data were transformed by getting the square root and adding 0.05 to each value. For the effect of genotype on root response, One-Way ANOVA was used and differences among means were determined at 5\% level of significance. For testing the effects of genotype, PGR treatment and exposure time, data were analyzed using Three Factorial ANOVA. Parameters with significant differences were subjected to Least Significant Difference (LSD) test to analyze differences between pairs of means. Analyses were done using SAS/STATver 14.1 (SAS Institute Inc., Cary, North Carolina, USA).

\section{Results and Discussion}

\section{General Observations}

After dragon fruit cuttings were acclimatized in the greenhouse for 50 days after planting, roots of dragon fruit cuttings were well established (Figure 2). New shoots also developed in $69 \%$ (75 out of 108) of the stem cuttings. Majority (70 out of 75) of these cuttings developed new shoots laterally, while a few ( 8 out of 75$)$ developed new shoots at the apex (Figures $3 \mathrm{~A}$ and $3 \mathrm{~B}$, respectively). It was also observed that the new shoots secreted fluids which appeared to attract red ants in the greenhouse. The new shoots infested with red ants were damaged and consequently died (Figure 3C). Twenty seven percent (30 out of 108) of the dragon fruit stem cuttings became putrid from stem rot. Twenty-seven (27) of these cuttings were salvaged by scraping off rotten parts at the base (Figure 3D), apex and lateral portions of the stem cuttings. The remaining three cuttings were not salvaged successfully due to the severity of rotting incidence (Figure 3E). These were not included in the data collection producing changes in the number of replicates for some treatments in the multifactorial experiment.

\section{Effect of Genotype}

Cuttings of 'Moroccan Red' genotype had the longest root system $(24.56 \pm 3.05 \mathrm{~cm})$ followed by 'Mexican White' $(22.28 \pm 4.36 \mathrm{~cm})$, 'Hawaiian White' $(19.39 \pm 1.50 \mathrm{~cm})$ and 'Royal Red' genotypes $(18.67 \pm 2.41 \mathrm{~cm})$ (Table 2). However, root lengths were not statistically different from each other. The 'Red' genotypes recorded earlier days of sprouting and produced more roots than the 'White' genotypes. The mean values, however, were also not statistically different among dragon fruit genotypes. On the other hand, the number of new shoots differed among genotypes $(\mathrm{P}<0.05)$.

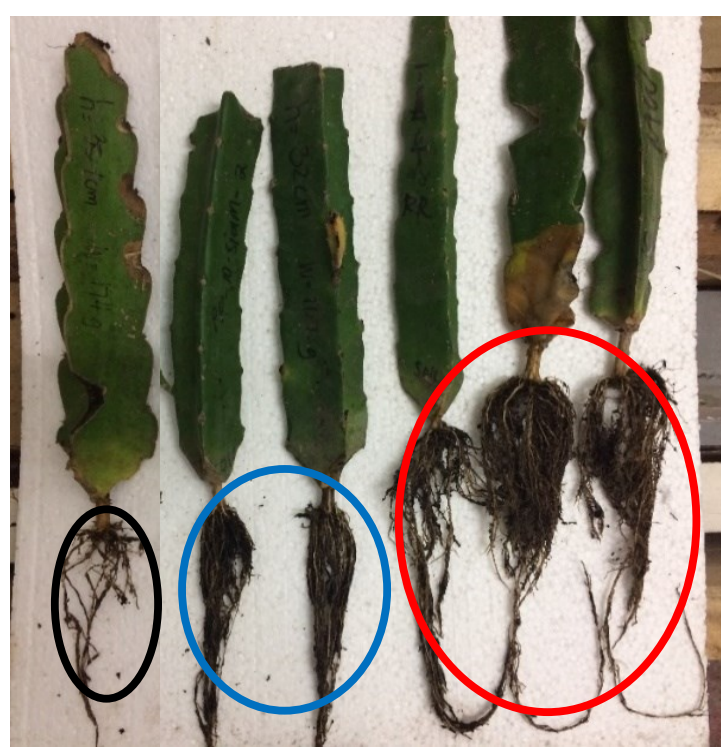

Figure 2. Dragon fruit stem cuttings acclimatized in the greenhouse with sparse lateral roots attached to the main roots (black circle); longer and more lateral roots attached to the main roots (blue circle) and bushy root system and an apparent longer root (red circle). 

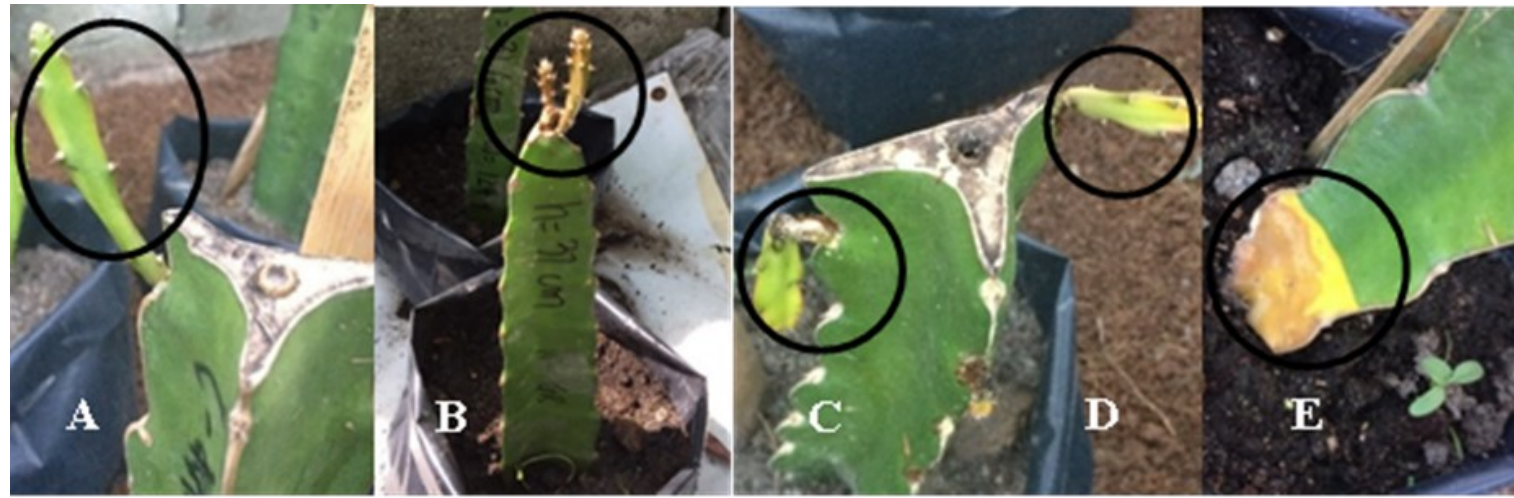

Figure 3. Dragon fruit cuttings acclimatized in the CNSM, MSU-GSC greenhouse with $40 \%$ shading and an average noontime and daytime $(9: 00 \mathrm{am})$ temperature of $33.2^{\circ} \mathrm{C}$ and $25.4^{\circ} \mathrm{C}$, respectively: (A) lateral shoot formation (circle); (B) apical shoot formation (circle); (C) damaged new shoots (circle) due to ant infestation; (D) basal stem rot (circle);

(E) stem rot on the entire stem cutting (circle).

Both 'Red' genotypes developed more shoots $(1.44 \pm 0.20$ new shoots for 'Royal Red'; $1.89 \pm 0.34$ new shoots for 'Moroccan Red'), which were significantly different from 'Hawaiian White', the genotype with the fewest number of new shoots $(0.67 \pm 0.23)$. While shoot number for 'Mexican White' $(1.22 \pm 0.32$ new shoots $)$ did not significantly differ numerically from that of the 'Red' genotypes, 'Mexican White' still produced fewer shoots along with 'Hawaiian White'.

A previous study reported that dragon fruit with red-pulped fruits generated a higher number of new shoots than the white-pulped genotypes under no auxin treatment [10]. In our study, the lower number of new shoots for the 'White' genotypes may be related to ant infestation. Fourteen (14) out of 26 cuttings used in the single experiment were 'White' genotypes infested with ants. Stem bud damage was apparent as soon as buds come out. Because the onset of ant infestation was at a very early stage of bud outgrowth, these buds were likely missed during counting; hence, the lower number of shoots in 'White' genotypes. Fully developed stems that were also damaged by ants became shriveled and were not counted, which also contributed to the lower number of shoots for 'White' genotypes.

Secretions were also observed from buds of stem cuttings. These secretions were suspected to contain secondary metabolic compounds that may be attractive to ants. These compounds are known to be selectively produced in any plant organ [12]. Most of the secondary metabolites produced by plants of the family Cactaceaeare aromatic substances such as phenols, which possess insect-repelling or insecticidal activities [13]. Varying levels of phenol in plants have different effects on insects. For instance, wheat cultivars with high concentrations of phenolic compounds were less attractive to cereal aphids than cultivars with low phenolic concentrations [14]. The concentration of phenols in secretions from dragon fruit buds and its effect on ants is worth investigating further for proper pest control.

\section{Multifactorial Experiment}

PGR formulation and immersion time, as single factors, did not produce any significant effect on all the root and shoot growth responses at $\alpha=0.05$ (Table 3). Genotype, PGR formulation,

Table 2. Means of the root and shoot growth parameters of the dragon fruit genotypes used in the single factorial experiment under greenhouse acclimatization conditions.

\begin{tabular}{lcccc}
\hline \multicolumn{1}{c}{ Genotype } & $\begin{array}{c}\text { Root length } \\
\text { ns }\end{array}$ & No. of roots ${ }^{\text {ns }}$ & $\begin{array}{c}\text { No. of days to first } \\
\text { shoot emergence } \text { en }^{\text {ns }}\end{array}$ & $\begin{array}{c}\text { No. of new shoots } \\
(P<0.05)^{*}\end{array}$ \\
\hline Hawaiian White & $19.39 \pm 1.50$ & $9.56 \pm 1.33$ & $37.11 \pm 4.82$ & $0.67 \pm 0.23^{\mathrm{b}}$ \\
Mexican White & $22.28 \pm 4.36$ & $9.33 \pm 1.83$ & $38.67 \pm 3.40$ & $1.22 \pm 0.32^{2^{\mathrm{ab}}}$ \\
Royal Red & $18.67 \pm 2.41$ & $10.78 \pm 2.27$ & $36.56 \pm 2.81$ & $1.44 \pm 0.20^{\mathrm{a}}$ \\
Moroccan Red & $24.56 \pm 3.05$ & $10.33 \pm 1.66$ & $36.89 \pm 3.27$ & $1.89 \pm 0.34^{\mathrm{a}}$ \\
\hline
\end{tabular}

Means followed by the same letter(s) are not significantly different at $\alpha=0.05$. 
immersion time and their interactions did not have significant effects also on all the root and shoot growth responses. The dilution of the commercial PGRs may be a major reason for the lack of interaction among factors tested. The concentrations employed may be too low. The response of auxins in enhancing rooting performance is also species specific, thus, the optimum concentration and combination of auxins may differ among species [15] or even varieties. In fact, a study on cactus pear showed that the root length decreased with increasing concentrations of auxins from $5,000 \mathrm{mg} \cdot \mathrm{l}^{-1}$ to $10,000 \mathrm{mg} \cdot \mathrm{l}^{-1}$ [15]. Moreover, the high auxin concentrations (6000 to $7000 \mathrm{mg} . \mathrm{l}^{-1}$ ) used from previous studies on dragon fruit did reveal significant responses between white and red-pulped varieties of dragon fruit [9-10].

The time of immersion may have further contributed to the lack of significant differences on the root and shoot responses to the three factors tested. Auxins at low concentration were recommended to be applied for several days, while those at high concentration may be treated for a shorter period of time (several seconds or minutes) [16]. This mechanism is important because the efficacy of auxins depends on the concentration that reaches the target cells. Our data suggest that an immersion time of 15 min may be considered insufficient for effective hormone uptake.

The length of observation period is a third factor to consider in growth responses. In our study, we followed the 50 day-observation period to simulate the grower's practice of acclimatizing cuttings prior to field transplanting. By this time, cuttings have developed an extensive root system and grown multiple shoots; thus, any slow-growing or slow-responding individuals may have had sufficient time to catch up with faster growing individuals. In fact, one study on dragon fruit utilized three different times (30,60, and 90 days) to compare the effect of treatment period [9]. At 30 days, significant differences in root and shoot growth responses were already observed.

Genotype alone produced a significant effect on the number of new shoots and days to first shoot emergence $(\mathrm{P}<0.05)$ (Table 4). The number of new shoots of 'Royal Red' $(1.89 \pm 0.27)$ differed significantly $(\mathrm{P}<0.05)$ from those of the 'White' genotypes. 'Royal Red' did not differ from 'Moroccan Red' which produced $1.45 \pm 0.33$ shoots on the average. While the latter had significantly higher number of new shoots than 'Moroccan White' $(0.28 \pm 0.13)$, it did not differ significantly from 'Hawaiian White' $(0.95 \pm 0.31)$.

The time of emergence of first shoot for 'Royal Red' was earliest among the four genotypes at $35.12 \pm 0.20$ days (Table 4). While this was not significantly different from that of 'Moroccan Red', it was significantly shorter than that of 'Mexican White' (48.17 \pm 2.66 days) and 'Hawaiian White' (42.84 \pm 1.82 days). 'Moroccan Red', having the second shortest days to first shoot emergence (39.78 \pm 0.21 days), differed significantly from 'Mexican White' but not from 'Hawaiian White'. Altogether, the data suggest that 'Royal Red', and perhaps 'Moroccan Red' as well, has better

Table 3. Three factorial ANOVA summary for the individual factors and their interaction effects on the root and shoot growth of dragon fruit cuttings used in the multifactorial experiment.

\begin{tabular}{lcccccccc}
\hline \multirow{2}{*}{ Factors Tested } & \multicolumn{2}{c}{ Root length $(\mathrm{cm})$} & \multicolumn{2}{c}{ No. of roots } & \multicolumn{2}{c}{$\begin{array}{c}\text { No. of days to first } \\
\text { shoot emergence }\end{array}$} & \multicolumn{2}{c}{ No. of new shoots } \\
\cline { 2 - 9 } & F & Sig. & F & Sig. & F & Sig. & F & Sig. \\
\hline Genotype & $0.627 \mathrm{~ns}$ & 0.601 & $1.983 \mathrm{~ns}$ & 0.129 & $4.552^{* *}$ & 0.007 & $7.971^{* *}$ & 0.000 \\
Immersion Time & $0.016 \mathrm{~ns}$ & 0.899 & $1.283 \mathrm{~ns}$ & 0.263 & $1.201 \mathrm{~ns}$ & 0.279 & $0.901 \mathrm{~ns}$ & 0.347 \\
PGR formulation & $0.177 \mathrm{~ns}$ & 0.838 & $0.133 \mathrm{~ns}$ & 0.876 & $0.600 \mathrm{~ns}$ & 0.553 & $0.588 \mathrm{~ns}$ & 0.559 \\
$\begin{array}{l}\text { Immersion time and } \\
\text { genotype }\end{array}$ & $1.204 \mathrm{~ns}$ & 0.318 & $0.605 \mathrm{~ns}$ & 0.615 & $0.224 \mathrm{~ns}$ & 0.880 & $0.679 \mathrm{~ns}$ & 0.569 \\
$\begin{array}{l}\text { Genotype and PGR } \\
\begin{array}{l}\text { Immersion Time and } \\
\text { PGR }\end{array}\end{array}$ & $0.782 \mathrm{~ns}$ & 0.588 & $1.491 \mathrm{~ns}$ & 0.202 & $0.151 \mathrm{~ns}$ & 0.988 & $0.626 \mathrm{~ns}$ & 0.709 \\
$\begin{array}{l}\text { Genotype, Immersion } \\
\text { Time and PGR }\end{array}$ & $0.760 \mathrm{~ns}$ & 0.473 & $0.304 \mathrm{~ns}$ & 0.739 & $0.211 \mathrm{~ns}$ & 0.810 & $0.577 \mathrm{~ns}$ & 0.566 \\
\hline
\end{tabular}

** highly significant at $\alpha=0.05$, ns- not significant 
shoot growth responses than the 'White' genotypes. Similarly, a previous study reported that 'genotype' had a significant effect on the shoot growth performance of dragon fruits subjected to auxin treatment [10]. The red-pulped genotype recorded earlier days for sprouting (42.72 days) and showed the highest number of new shoots per cutting (3.70 new shoots). The lower number of new shoots may be attributed to the stem rot manifested on the cuttings used in the multifactorial experiment. Since rotten portions were removed to salvage the experiment, some buds may have also been lost. Since buds are initiators for new shoots, their removal would result to a lower count. Out of the 20 cuttings with stem rot, 17 belonged to the 'White' genotypes. This could be one reason for the low counts for 'White' genotypes.

\section{Conclusion}

Overall, our data suggest that most of the time, the 'Red' genotype, either 'Royal Red' or 'Moroccan Red', performed better than the 'White' genotypes in terms of shoot response. The 'Red' genotypes also appeared to be less prone to disease and ant infestation in the greenhouse which may be an indication of better tolerance to biological stressors. Our findings further indicate that the diluted concentrations of PGR formulations as well as the relatively brief exposure time of $10 \mathrm{~s}$ or 15 min cannot resolve differences in growth responses among the four dragon fruit genotypes under the conditions employed in this study.

The protocols that we used for preparing dragon fruit cuttings and the learnings on crop management are useful for acclimatizing cuttings in the greenhouse. We further demonstrated that a healthy root system develops and shoot induction occurs under the greenhouse conditions employed. The following recommendations were made to help establish the requirements of dragon fruit for greenhouse acclimatization and practical management practices for field application. First, the observation period for growth response testing may be shortened to ensure that fine differences are detected. We recommend that a week after first shoot emergence (20-30 days), the roots should already be examined. Known concentrations of PGRs may be tested, with the actual label rates as control. Second, with diluted concentrations (below levels that have been tested in the literature), a much longer time of exposure is recommended. Finally, to avoid ant and stem rot infestation which can bias the results and delay field transplanting in actual farm practice, proper pest management strategy must be applied in a timely manner.

\section{Acknowledgment}

This study was funded by the Mindanao State University (MSU) General Santos intramural research grant. We thank Mariahnne Pasaul of Maryland Dragon Fruit Gardens for her technical support and for providing us with stem cuttings; Jeanette Madas of the Science Department, MSU-General Santos for her critic; and Edgardo Salut of the College of Agriculture, MSU General Santos, and Larni Angellie Espada for their assistance in our statistical analyses.

\section{References}

[1] Ortiz-Hernández, Y. D., \& Carrillo-Salazar, J. A. (2012). Pitahaya (Hylocereus spp.): a short review. Comunicata Scientiae, 3(4), 220-237.

[2] [FFTC] Food and Fertilizer Technology Center-Agricultural Policy Platform (2018). Dragon fruit production in Vietnam: achievements and challenges. Retrieved from http:// ap.fftc.agnet.org/ap_db.php?id=873\&print=1 .

[3] [PSA] Philippine Statistics Authority (2018). Dragon fruit area planted in the Philippines per region and province: 2012-2017. Crops Statistics Division, Philippines Statistics Authority, Quezon City, Philippines.

[4] [FFTC] Food and Fertilizer Technology Center - Agricultural Policy Platform (2018). Current status of dragon fruit and its prospects in the Philippines. Retrieved from http://ap.fttc.agnet.org/ index.php.

[5] Bellec, F., Vaillant, F., and Imbert, E. (2006). Pitahaya (Hylocereus spp.): a new fruit crop, a market with a future. Fruits, 61, 237-250. doi: 10.1051/fruits:2006021 www.edpsciences.org/ fruits

[6] Jaafar, A. (2009). Proximate analysis of dragon fruit (Hylocereus polyrhizus). American Journal of Applied Sciences, 6, 1341-1346. doi: 10.3844/ ajassp.2009.1341.1346.

[7] Merten, S. (2003). A review of Hylocereus production in the United States. Professional 
Association for Cactus Development, 98-105. doi: 10.1177/0020764006067234.

[8] Blythe, K., Sibley, J., Tilt, K., and Ruter, J. (2007). Methods of auxin application in cutting propagation: a review of 70 years of scientific discovery and commercial practice. Journal of Environmental Horticulture, 25, 166-185. Retrieved from http:// www.nurserycropscience.info/propagation/timingof-cutting-collection/technical-pubs/blythe-rootinghormone-review-jeh-25-3-166-185.pdf.

[9] Ayesha, S. and Thippesha, D. (2018). Influence of plant growth regulators on rooting of stem cuttings in dragon fruit (Hylocereus undatus). International Journal of Chemical Studies, 6, 1834 -1839 .

[10] Dhruve, L., Suchitra, V., Vani, V. S., Subbaramamma, P., and Saravanan, L. (2018). Rooting and shooting behaviour of red and white pulped varieties of dragon fruit (Hylocereus undatus) in relation to indole butyric acid concentrations. International Journal of Agricultural Sciences, 14, 229-234. doi: 10.15740/ HAS/IJAS/14.1/229-234.

[11] Loach, K. (1987). Hormone applications and adventitious root formation in cuttings - a critical review. Acta Horticulturae, 126-133. doi: 10.17660/actahortic.1988.227.19.

[12] Bennett, R. N., and Wallsgrove, R. M. (1994). Secondary metabolites in plant defense mechanisms. New Phytologist, 127, 617-633. doi: 10.1111/j.1469-8137.1994.tb02968.x.

[13] Zepeda, R. E., Estrada, M., Ocaña, A., Villegas, I., Brunner, I., and Bustos, E. (2009). Secondary metabolites induction in Mammillaria huitzilopochtli (Cactaceae) and evaluation of the fungicidal activity. African Journal of Biotechnology, 8(16), 3874-3878.

[14] Kaur, H., Salh, P. K., and Singh, B. (2017). Role of defense enzymes and phenolics in resistance of wheat crop (Triticum aestivum L.) towards aphid complex. Journal of Plant Interactions, 12, 304-311. doi: 10.1080/ 17429145.2017.1353653.

[15] Shehu, U. I., Sani, L. A., and Ibrahim, A. B. (2016). Auxin induced rooting of cactus pear
(Opuntia ficus-indica L. Miller) cladodes for rapid on-farm propagation. African Journal of Agricultural Research, 11, 898-900. doi: 10.5897/ AJAR2015.10592.

[16] De Klerk G.J., van der Krieken W. and de Jong J. (1999). Review the formation of adventitious roots: New concepts, new possibilities. In Vitro Cell Develop Biol Plant, 35, 189-199. 